\title{
Astronomia, história da ciência e ensino de física: um projeto interdisciplinar
}

\author{
Astronomy, history of science and physics teaching: an \\ interdisciplinary project
}

\section{Gil Alves Silva}

Programa de Pós-Graduação em História das Ciências e das Técnicas e Epistemologia (HCTE), Universidade Federal do Rio de Janeiro (UFRJ)

gilalvessilva@yahoo.com.br

orcid.org/0000-0002-1263-2625

Resumo. A astronomia é provavelmente a mais antiga de todas as ciências. Observar o céu sempre incitou a curiosidade e a busca por explicações para os fenômenos da natureza. Infelizmente, as temáticas que envolvem essa ciência ainda são pouco exploradas ao longo da vida escolar, com seus conteúdos sendo abordados por professores de ciências no ensino fundamental e física durante o ensino médio. Tratar o tema astronomia no ensino médio se apresenta como uma questão crucial para os professores dessa disciplina. Como a atual legislação estabelece que as aulas devem atender a quesitos como contextualização e interdisciplinaridade, propõe-se que conteúdos envolvendo História da Ciência possam tornar essas aulas mais atrativas. Nesse trabalho, dessa forma, inserimos conteúdos astronômicos nas aulas de física via História da Ciência visando a obtenção de um ensino mais rico e integrado.

Palavras-chave: Astronomia. Ensino de física. História da ciência.

Abstract. Astronomy is probably the oldest of all sciences. Observing the sky has always sparked curiosity and the search for explanations for the phenomena of nature. Unfortunately, the themes surrounding this science are still little explored throughout school life, with its contents being addressed by science teachers in elementary and physical education during high school. Treating the topic of astronomy in high school is a crucial issue for teachers in this discipline. As the 
current legislation establishes that classes must meet issues such as contextualization and interdisciplinarity, it is proposed that content involving the History of Science can make these classes more attractive. In this work, in this way, we insert astronomical content in physics classes via History of Science aiming at obtaining a richer and more integrated teaching.

Keywords: Astronomy. Physics teaching. History of scienc

Recebido: 01/10/2017 Aceito: 27/10/2017 Publicado: 06/11/2017

\section{Introdução}

Frequentemente, a História da Ciência (HC) aparece em apêndices (ou seção denominada "curiosidades") em alguns capítulos de livros didáticos. Dessa forma, a HC é apresentada ao estudante como algo completamente desconexo em relação ao conteúdo trabalhado (GUTTMANN; BRAGA, 2015). Porém, sua utilização pode transformar a maneira como se trabalha a física em sala de aula, rompendo com o paradigma vigente, no qual os fenômenos físicos são descritos, predominantemente, pela linguagem matemática. Assim, através da interdisciplinaridade ${ }^{1}$, a física pode se reinventar, apresentando-se como uma disciplina capaz de dialogar com as outras, ultrapassando o tradicional e mostrando que não está limitada apenas à matemática (GUTTMANN; BRAGA, 2015).

Nesse caso, nossa proposta de interdisciplinaridade visa inserir conteúdos astronômicos nas aulas de física via HC. O tema escolhido foi Leis de Kepler do movimento planetário. Antes que o astrônomo alemão Johannes Kepler determinasse tais leis, no começo do século XVII, a tarefa dos astrônomos praticamente se resumia a elaborar um sistema cosmológico que explicasse as trajetórias aparentes dos planetas no céu como uma combinação de movimentos circulares uniformes - um dogma com mais de dois milênios que remonta aos filósofos gregos Pitágoras, Platão e Aristóteles. Baseado na cosmologia desse último o astrônomo grego Claudio Ptolomeu criou um sistema onde a Terra ficava posicionada no centro do universo, imóvel, com a Lua, o Sol e os outros planetas girando ao seu redor. Esse modelo de cosmo geocêntrico esteve em evidência até a metade do século XVI, quando foi rivalizado pelo sistema heliocêntrico do astrônomo polonês Nicolau Copérnico, que colocou todos os astros - inclusive a Terra -

\footnotetext{
1 "Compreender a ciência como um empreendimento humano, construído histórica e socialmente". Este é um dos objetivos gerais da área de ciências da natureza na educação básica que consta na Base Nacional Comum Curricular (BNCC), do Ministério da Educação (MEC). A componente curricular de física do $1^{\circ}$ ano do ensino médio deixa implícito, nos tópicos que abrangem o conhecimento conceitual, que serão abordados conteúdos relativos à astronomia, entre eles as leis do movimento planetário - mais conhecidas como Leis de Kepler.
} 
orbitando ao redor do Sol, que ocupava o lugar do nosso planeta como centro do universo. No final desse século também foi alvo de discussão um sistema híbrido - um misto de geocentrismo com heliocentrismo - criado pelo astrônomo dinamarquês Tycho Brahe, onde a Terra permanecia estática no centro do universo, com a Lua e o Sol em sua órbita - embora os planetas girassem ao redor do Sol, como no cosmo copernicano. Baseado nas observações de Tycho, Kepler revoluciona a astronomia, libertando-a de seus velhos dogmas ao descrever as órbitas planetárias como elipses com movimentos não uniformes - uma total ruptura com a harmonia divina dos antigos.

O brevíssimo resumo proposto acima se refere a como mais de dois milênios de história do pensamento astronômico foram sintetizadas naquilo que, para a posteridade, ficou conhecido como sendo as Leis de Kepler do movimento planetário. Seguem seus enunciados segundo Oliveira \& Saraiva (2004):

$1^{\text {a }}$ Lei: A órbita de cada planeta é uma elipse, com o Sol em um dos focos. Como consequência da órbita ser elíptica, a distância do Sol ao planeta varia ao longo de sua órbita.

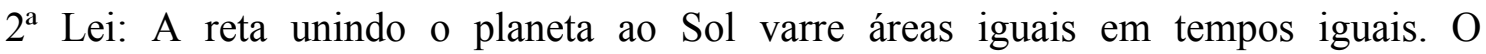
significado físico desta lei é que a velocidade orbital não é uniforme, mas varia de forma regular: quanto mais distante o planeta está do Sol, mais devagar ele se move.

$3^{\text {a }}$ Lei: O quadrado do período orbital dos planetas é diretamente proporcional ao cubo de sua distância média ao Sol. Esta lei estabelece que planetas com órbitas maiores movem-se mais lentamente em torno do Sol e, portanto, isso implica que a força ${ }^{2}$ entre o Sol e o planeta decresce com a distância ao Sol. Sendo $P$ o período sideral do planeta, $a$ o semieixo maior da órbita (igual à distância média do planeta ao Sol), e $K$ uma constante, podemos expressar a $3^{\mathrm{a}}$ lei como: $P^{2}=K a^{3}$.

Lançados num livro didático, esses enunciados até podem atingir seu propósito - a compreensão e utilização dessas leis para explicar a cinemática planetária, mas provavelmente terão pouco apelo junto aos estudantes do ensino médio. Nosso trabalho propõe uma abordagem diferente ao inserir uma contextualização histórica no tema, ou seja, identificar um problema - como explicar o movimento dos planetas e por que suas velocidades variam ao longo de suas órbitas, e reconhecer alguns dos impactos e mudanças socioculturais oriundos da tentativa de solucioná-lo. Através da HC temos a oportunidade de visualizar essa descoberta de outra forma, levando em consideração não somente o aspecto científico da descoberta, mas também os aspectos sociais, políticos, econômicos, culturais, religiosos e filosóficos. Visto dessa maneira, não há dúvida que alguns pontos dessa história chamarão a atenção dos estudantes, propondo reflexões sobre a vida e as ideias dos personagens principais - ponderações que muito provavelmente não ocorreriam sem o uso da HC.

\footnotetext{
${ }^{2}$ Enquanto a astronomia de sua época estava preocupada somente em descrever os movimentos dos objetos celestes, Kepler procurou encontrar as causas desses movimentos, acreditando que deveria haver alguma espécie de força - alguma interação entre o Sol e os planetas que seria responsável pelas suas órbitas.
} 
Nosso objetivo, portanto, é traçar um breve panorama histórico dos principais sistemas cosmológicos ocidentais - dos gregos até Kepler, mostrando como refinamentos nesses sistemas e novas observações levaram à elaboração das leis do movimento planetário. À parte da maneira como são tradicionalmente apresentadas no ensino médio (enunciados, fórmulas etc.), nosso propósito é chegar às Leis de Kepler via história da cosmologia, estimulando uma reflexão de como a $\mathrm{HC}$ pode ser usada como ferramenta pedagógica para o ensino de física.

\section{Público alvo}

A sequência didática destina-se a estudantes do nível médio que estejam cursando a disciplina de mecânica clássica ou equivalente. $O$ material também pode ser usado/adaptado para a formação de professores de ciências/física em cursos de licenciatura, conforme se vê na Seção 4.

\section{Sequência didática}

O trabalho está programado para ser desenvolvido ao longo de dois tempos de quarenta e cinco (ou cinquenta) minutos cada. Será entregue um texto didático (SILVA, 2016) aos estudantes antecipadamente, para que este possa ser lido em casa e também fornecer apoio para o acompanhamento das aulas, onde se inclui a apresentação de slides. No texto, os estudantes terão acesso a todas as referências bibliográficas aqui citadas e poderão ainda consultar outras (livros e sites). O primeiro tempo será uma apresentação de slides onde será exposto o tema "Leis de Kepler: um breve panorama de como a história da cosmologia mostra sua descoberta". No tempo seguinte haverá uma discussão do tema com a turma de como o conhecimento científico se desenvolve num contexto sociocultural e é influenciado por fatores extrínsecos à ciência. Para finalizar será feito um exercício escrito de verificação da aprendizagem, onde serão abordados aspectos quantitativos relacionados às distâncias e períodos de revolução dos planetas em relação ao Sol ( $3^{\text {a }}$ Lei de Kepler).

\subsection{Descrição sumária da sequência didática}

É importante destacar que o uso da $\mathrm{HC}$ tem como principal propósito transmitir ao estudante - que está em processo de construção do conhecimento - que as ideias aceitas atualmente são um produto de muitas experiências e observações que foram aceitas pela comunidade científica e outras que fracassaram. Assim, o texto utilizado foi elaborado com o objetivo de apresentar, dentro de um contexto histórico, como se desenvolveu nosso pensamento acerca do movimento dos astros. 
Embora o recorte cronológico pareça muito extenso (da antiguidade até o começo do século XVII), o recorte espacial é bem mais definido (apenas Europa). Na impossibilidade de reprodução de todo o período histórico estudado, o texto mostra os episódios considerados relevantes para alcançar nosso objetivo. Assim, o texto utilizado está dividido em cinco etapas, cujas principais características descreveremos a seguir.

Nas duas primeiras etapas (itens 1 e 2) foram destacadas as qualidades da ciência grega, que apareceram pela primeira vez com Tales de Mileto (c.624-546 AEC). Nessa linha também estão Anaximandro de Mileto (c.610-547 AEC), contemporâneo mais jovem de Tales; Pitágoras de Samos (c.570-495 AEC), quem primeiro tentou explicar o movimento do Sol e dos planetas pela combinação de movimentos circulares uniformes; Filolau de Croton (c.470-385 AEC), discípulo de Pitágoras; Platão (c.427-348 AEC), discípulo de Sócrates e considerado uma das figuras mais importantes do mundo grego; Aristóteles (384-322 AEC), aluno de Platão e considerado um dos mais influentes filósofos gregos; Aristarco de Samos (c.310-230 AEC), o primeiro astrônomo a propor um sistema heliocêntrico (com o Sol estacionário no centro do universo); Hiparco de Nicéia (c.190-125 AEC), considerado por muitos o maior observador celeste da antiguidade, e Claudio Ptolomeu (c.100-178) - o ápice e último grande nome científico da antiguidade grega, cujo modelo geocêntrico do cosmo dominou a astronomia por quatorze séculos.

O texto revela que os pensadores gregos começaram como filósofos que quiseram dar sentido ao mundo físico em que viviam. Utilizaram círculos e esferas em cosmologia inovações fundamentais. Antes deles as cosmovisões não tinham nenhum compromisso com a razão, e as explicações para os fenômenos da natureza tinham causas sobrenaturais ou teológicas. Parece que coube aos gregos refutar todas as lendas e folclores, e, mesmo com as limitações de suas cosmologias, começam a surgir esquemas coerentes da criação, onde hipóteses sustentadas por leis naturais começam a substituir as mitologias anteriores.

$\mathrm{Na}$ terceira etapa (item 3) é apresentado o modelo heliocêntrico de Nicolau Copérnico (1473-1543). Assim como Aristarco, Copérnico achava que o cosmo perfeito surgiria se o Sol fosse colocado no centro do universo e a Terra passasse a ser vista como um planeta percorrendo uma órbita em torno dele. Ao longo do texto vamos notar que o principal objetivo de Copérnico não era subverter a astronomia, mas retomar o principal preceito platônico: a crença no movimento circular uniforme como o mais adequado para descrever as trajetórias dos astros. Iniciada mais de meio século após a sua morte, sua revolução surgiu justamente por ele ser um conservador, e seu maior mérito reside no fato de ter incitado astrônomos posteriores (como Kepler e Galileu) a imaginar um cosmo heliocêntrico.

Nas duas últimas etapas (itens 4 e 5) apresentamos os astrônomos Tycho Brahe (15461601) e Johannes Kepler (1571-1630), cujas vidas e obras estão intimamente ligadas. Resumidamente, podemos dizer que Tycho possuía as melhores observações da era prételescópio. Acreditando que nosso planeta estava imóvel no centro do cosmo, formulou sua própria cosmovisão, onde a Terra permanecia fixa no centro do universo, com a Lua 
e o Sol em sua órbita - embora admitisse que os planetas pudessem orbitar ao redor do Sol. Enquanto Tycho se dedicou exclusivamente às observações astronômicas, Kepler buscou a ordem cósmica através de religiosidade e matemática. Utilizando as observações de Tycho mostrou que as leis do movimento planetário tinham que ser revistas: em vez do movimento circular uniforme em torno da Terra, estava claro que os planetas se moviam em órbitas elípticas ao redor do Sol (e a velocidades variáveis). Essa sensacional combinação entre teoria e prática proporcionou um dos mais extraordinários e proveitosos encontros da história da astronomia. Tycho e Kepler conviveram pouco, mas o suficiente para trazer ao mundo o verdadeiro embrião da ciência moderna.

\section{Atividade complementar}

O presente projeto também pode fortalecer a formação de professores dos cursos de licenciatura - ou o aperfeiçoamento daqueles já formados, particularmente aqueles cujas áreas permitem que seja abordada a temática astronômica. A fim de atingir esse objetivo seria criada uma disciplina para ser dada na graduação, por exemplo, Tópicos em astronomia ou Introdução à astronomia, onde seriam alternadas aulas e atividades em espaços de educação não formal, como planetários ou museus de ciência, e o conteúdo visto em sala de aula seria articulado com palestras junto aos licenciandos e observação do céu com instrumentos e a olho nu.

Nesse sentido, as temáticas das aulas/palestras seriam focadas em: reconhecer ordens de grandeza de medidas astronômicas (ou seja, se familiarizar com dimensões e distâncias dos astros), conhecer as relações entre os movimentos do sistema Sol-Terra-Lua para a descrição de fenômenos astronômicos (duração do dia/noite, estações do ano, fases da Lua, eclipses etc.), noções de esfera celeste, movimento diurno dos astros, constelações etc. Os aspectos históricos precederiam todos os tópicos supracitados.

Ao final do curso espera-se que os estudantes sejam capazes de desenvolver textos e/ou metodologias de ensino de astronomia que possam ser utilizados em sala de aula dentro de suas respectivas disciplinas (por exemplo, as condições para a formação de moléculas orgânicas complexas no meio interestelar e a origem da vida, assuntos que envolvem disciplinas como a química e a biologia), e que, preferencialmente, tenham uma abordagem histórica (por exemplo, estudar a história do desenvolvimento dos telescópios, as contribuições de Galileu e Kepler nesse processo e a física presente na formação de imagens por instrumentos ópticos, assunto da óptica geométrica).

\section{Considerações Finais}

Então, embora as Leis de Kepler tenham sido lançadas e estabelecidas no princípio do século XVII, a montagem do cenário ocorreu bem antes: começou com a geometrização 
da esfera celeste pelos gregos, prosseguiu ao longo do século XVI com o desenvolvimento e (gradual) aceitação da teoria copernicana, e culminou com as meticulosas observações de Tycho Brahe. Esses foram apenas alguns dos ingredientes que permitiram a Kepler elaborar suas leis do movimento planetário.

Nesse sentido, espera-se que o estudante possa reconhecer o estudo da física como um processo cuja construção ocorreu ao longo da história da humanidade, impregnado de contribuições culturais, econômicas e sociais. A inclusão de história da ciência é necessária para se evitar a ideia de o conhecimento científico ser um sistema fechado de verdades absolutas. Abordagens históricas no ensino de física e de ciências podem ajudar no processo de mudança conceitual dos estudantes sobre os temas em questão e estimular o pensamento crítico, elucidando melhor a atividade científica em si e sua relação com os contextos sociais e culturais onde esta se dá.

\section{Financiamento}

O presente trabalho foi realizado com apoio da Coordenação de Aperfeiçoamento de Pessoal de Nível Superior - Brasil (CAPES) - Código de Financiamento 001.

\section{Referências}

GUTTMANN, G.; BRAGA. M. Universo dinâmico e Big Bang: uma outra forma de se abordar o Cosmo no Ensino Médio. In: SILVA, A. P. B.; GUERRA, A. (org.). História da Ciência e Ensino: Fontes Primárias e propostas para sala de aula. São Paulo: Editora Livraria da Física, 2015, p. 137-147.

MOURÃO, R. R. F. Kepler: a descoberta das leis do movimento planetário. São Paulo: Odysseus Editora, 2003.

OLIVEIRA, K.; SARAIVA, M. F. Astronomia e astrofísica. 2. ed. São Paulo: Livraria

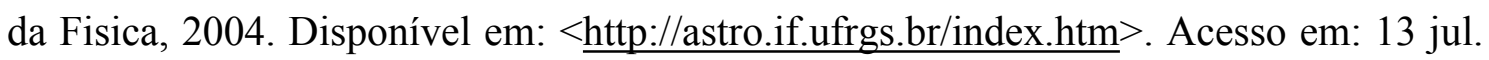
2017.

SILVA, G.A. Leis de Kepler do movimento planetário: um breve panorama de como a história da cosmologia mostra sua descoberta. In: $15^{\circ}$ SEMINÁRIO NACIONAL DE HISTÓRIA DA CIÊNCIA E DA TECNOLOGIA, 2016, Florianópolis. Anais eletrônicos... São Paulo: SBHC, 2016. Disponível em: $<$ http://www.15snhct.sbhc.org.br/site/anaiscomplementares\#G $>$. Acesso em: 13 jul. 2017. 